University of Wollongong

Research Online

Faculty of Engineering and Information

Faculty of Engineering and Information

Sciences - Papers: Part A

Sciences

$1-1-2013$

\title{
Removal of emerging trace organic contaminants by MBR-based hybrid treatment processes
}

Luong Nguyen

University of Wollongong, Inn909@uowmail.edu.au

Faisal Ibney Hai

University of Wollongong, faisal@uow.edu.au

Jinguo Kang

University of Wollongong, jkang@uow.edu.au

William E. Price

University of Wollongong, wprice@uow.edu.au

Long D. Nghiem

University of Wollongong, longn@uow.edu.au

Follow this and additional works at: https://ro.uow.edu.au/eispapers

Part of the Engineering Commons, and the Science and Technology Studies Commons

Research Online is the open access institutional repository for the University of Wollongong. For further information contact the UOW Library: research-pubs@uow.edu.au 


\title{
Removal of emerging trace organic contaminants by MBR-based hybrid treatment processes
}

\begin{abstract}
The aim of this study was to demonstrate the complementarity of combining membrane bioreactor (MBR) treatment with UV oxidation or high pressure membrane filtration processes such as nanofiltration (NF) or reverse osmosis (RO) for the removal of trace organic contaminants ( $\mathrm{TrOC})$. The results suggest that the removal mechanisms of TrOC by either UV oxidation or NF/RO membrane filtration differ significantly from those of an MBR system. Thus, they can complement MBR treatment very well to significantly improve the removal of TrOC. MBR treatment can effectively remove hydrophobic and readily biodegradable hydrophilic TrOC. The remaining hydrophilic and biologically persistent TrOC were shown to be effectively removed by either UV oxidation or NF/RO membrane filtration. The combination of MBR with UV oxidation or NF/RO membrane filtration resulted in a removal ranging from $85 \%$ to complete removal (or removal to below the analytical detection limit) of all $22 \mathrm{TrOC}$ selected in this study. In particular, it is noteworthy that although MBR treatment and direct UV oxidation separately achieved low removal of carbamazepine (a widely reported problematic compound), the combination of these two processes resulted in more than $96 \%$ removal.
\end{abstract}

\section{Keywords}

treatment, processes, trace, organic, removal, contaminants, emerging, mbr, hybrid

Disciplines

Engineering | Science and Technology Studies

\section{Publication Details}

Nguyen, L., Hai, F. Ibney., Kang, J., Price, W. E. \& Nghiem, L. D. (2013). Removal of emerging trace organic contaminants by MBR-based hybrid treatment processes. International Biodeterioration and

Biodegradation, 85 (November), 474-482. 


\section{Removal of emerging trace organic contaminants by MBR-based hybrid treatment processes}

International Biodeterioration and Biodegradation 2013, 1-9

Luong N. Nguyen ${ }^{a}$, Faisal I. Hai ${ }^{a}$, Jinguo Kang ${ }^{a, b}$, William E. Price ${ }^{b}$ and Long D. Nghiem ${ }^{a}$

${ }^{a}$ Strategic Water Infrastructure Laboratory, School of Civil, Mining and Environmental Engineering, University of Wollongong, Wollongong, NSW 2522, Australia

${ }^{\mathrm{b}}$ Strategic Water Infrastructure Laboratory, School of Chemistry, University of Wollongong, Wollongong, NSW 2522, Australia

* Corresponding author: Long Duc Nghiem. Email: longn@uow.edu.au; Ph: +61 242214590. 


\section{RESEARCH HIGHLIGHTS:}

- MBR, UV oxidation, and NF/RO membranes remove TrOC based on different mechanisms.

- $\quad$ MBR could effectively remove hydrophobic and readily biodegradable TrOC.

- Chlorinated TrOC and TrOC with a phenolic group are readily degraded by UV oxidation.

- $\quad \mathrm{NF} / \mathrm{RO}$ membranes can effectively reject charged and hydrophilic TrOC.

- $\quad$ Thus, MBR-UV or MBR-NF/RO hybrid systems are very effective for removing TrOC. 


\section{Abstract}

The aim of this study was to demonstrate the complementarity of combining membrane bioreactor (MBR) treatment with UV oxidation or high pressure membrane filtration processes such as nanofiltration (NF) or reverse osmosis (RO) for the removal of trace organic contaminants (TrOC). The results suggest that the removal mechanisms of TrOC by either UV oxidation or NF/RO membrane filtration differ significantly from those of an MBR system. Thus, they can complement MBR treatment very well to significantly improve the removal of TrOC. MBR treatment can effectively remove hydrophobic and readily biodegradable hydrophilic TrOC. The remaining hydrophilic and biologically persistent TrOC were shown to be effectively removed by either UV oxidation or NF/RO membrane filtration. The combination of MBR with $\mathrm{UV}$ oxidation or NF/RO membrane filtration resulted in a removal ranging from $85 \%$ to complete removal (or removal to below the analytical detection limit of (or less than) $20 \mathrm{ng} / \mathrm{L}$ ) of all 22 TrOC selected in this study. Of particular interest was the fact that although MBR treatment and direct UV oxidation separately both achieved low removal of carbamazepine (a widely reported problematic compound), the combination of these two processes resulted in more than $96 \%$ removal.

Keywords: membrane bioreactor (MBR); trace organic contaminants (TrOC); UV oxidation; nanofiltration; reverse osmosis. 


\section{Introduction}

The occurrence of a significant number of trace organic contaminants (TrOC) in municipal wastewater and sewage-impacted water bodies has been identified as an emerging issue of environmental and health concern. Many TrOC have been ubiquitously detected in effluent from conventional sewage treatment plants at concentrations from a few nanograms per litre (ng/L) to several micrograms per litre $(\mu \mathrm{g} / \mathrm{L})$. Recent evidence points to adverse impacts of TrOC even at such low concentrations on aquatic organisms and potentially on human health (Schwarzenbach et al., 2010). The conventional activated sludge (CAS) wastewater treatment process may not be adequate for the effective removal of many TrOC (Paxéus, 2004, Sahar et al., 2011). Thus, in recent years, there have been a number of dedicated investigations on advanced treatment processes or their combinations to prevent the release of TrOC into the aquatic environment via effluent discharge. Examples of these advanced treatment processes include membrane bioreactor (MBR) (Tadkaew et al., 2011), UV oxidation (Lekkerkerker-Teunissen et al., 2012), high pressure membrane filtration processes such as nanofiltration (NF) and reverse osmosis (RO) (Nghiem et al., 2004), and activated carbon adsorption (Ternes et al., 2002).

MBR has been established as an alternative option to the CAS process (Visvanathan et al., 2000). In comparison to CAS, MBR offers several advantages such as smaller physical footprint and improved effluent quality. In terms of TrOC removal, MBR is effective for the removal of hydrophobic and readily biodegradable TrOC and less effective in removal of hydrophilic and biologically persistent TrOC (Tadkaew et al., 2011).

UV oxidation is another advanced treatment process that can be very effective for the removal of TrOC. However, influent with a high bulk organic content and/or high turbidity would require a very high UV dosage, rendering the process economically unattractive (Wu and Linden, 2008, Basile et al., 2011). Thus, this process is mostly used as a polishing step. Previous studies have shown that UV oxidation is capable of oxidizing taste and odour causing pollutants such as geosmin and methyl tert-butyl ether (Cater et al., 2000) and pesticides such as atrazine (Beltrain et al., 1994). More recently, the application of UV oxidation for the treatment of TrOC has also been investigated. Packer et al. (2003) reported that diclofenac is subject to rapid photodegradation, while ketoprofen and naproxen are mildly photodegraded. On the other hand, they found also that ibuprofen is not degradable by direct photolysis using natural sun light (Packer et al., 2003). Other compounds such as the topical antimycotic drugs naftifine, 
sulbentine, cloxiquin, tolnaftate, and chlophenesin have also been shown to be light sensitive (Thoma and Kübler, 1997). As noted above, the effectiveness of UV oxidation may be reduced by the presence of bulk organic matter in wastewater (Chong et al., 2010). This study noted that to ensure rapid photocatalytic reaction rate, the turbidity of the target wastewater should be kept below 5 NTU for optimal UV light utilization and photocatalytic reaction.

$\mathrm{NF} / \mathrm{RO}$ membrane filtration processes have also been used to produce high quality water from non-traditional sources such as brackish, seawater or secondary treated wastewater (Shannon et al., 2008). Recent studies have demonstrated the excellent capacity of NF/RO to remove a large range of TrOC in pilot and full scale applications (Bellona et al., 2008, Al-Rifai et al., 2011). Physicochemical parameters such as molecular size, hydrophobicity and polarity as well as feed solution composition are considered important factors which govern NF/RO efficiency (Bellona et al., 2004). According to Nghiem et al. (2004), the removal of some hydrophobic compounds can be lower than that predicted based solely on a size exclusion mechanism. This is because hydrophobic compounds can also adsorb to NF/RO membranes and then diffuse through the dense polymeric matrix, resulting in considerable transport of these compounds across the ultrathin active skin layer. Another potential drawback of the NF/RO processes is membrane fouling which can be caused by the deposition of bulk organic or colloidal matter on the membrane surface if the feed solution is not adequately pre-treated.

When deployed on an individual basis, even the above mentioned advanced processes exhibit some inherent potential drawbacks and do not offer a complete barrier to a large range of TrOC that may occur in municipal wastewater. However, it appears that a hybrid system consisting of complementary advanced treatment processes can be very effective for the removal of these TrOC. Indeed, we have recently demonstrated the complementarity between MBR treatment and activated carbon adsorption for the removal of 22 TrOC (Nguyen et al., 2012). On the other hand, little is known about the complementarity between MBR treatment and other advanced treatment processes including UV oxidation or NF/RO membrane filtrations with respect to the removal of TrOC. To date, there have been only a very few studies on the application of integrated MBR-UV oxidation treatment process for the removal of TrOC (Laera et al., 2011, Köhler et al., 2012) and MBR-NF/RO membrane filtration (Alturki et al., 2010).

The aim of this study is to examine the removal of TrOC by an MBR-based hybrid treatment process consisting of MBR treatment with UV oxidation or with NF/RO membrane filtration. 
Removal mechanisms of the selected TrOC by each treatment process are considered based on their physicochemical properties to highlight the complementarity of the treatment processes.

\section{Materials and Methods}

\subsection{Synthetic wastewater and model TrOC}

A synthetic wastewater containing glucose $\left(400 \mathrm{mg} \mathrm{L}^{-1}\right)$, peptone $\left(100 \mathrm{mg} \mathrm{L}^{-1}\right), \mathrm{KH}_{2} \mathrm{PO}_{4}(17.5$ $\left.\mathrm{mg} \mathrm{L}^{-1}\right), \mathrm{MgSO}_{4}\left(17.5 \mathrm{mg} \mathrm{L}^{-1}\right), \mathrm{FeSO}_{4}\left(10 \mathrm{mg} \mathrm{L}^{-1}\right), \mathrm{CH}_{3} \mathrm{COONa}\left(225 \mathrm{mg} \mathrm{L}^{-1}\right)$ and $\left(\mathrm{NH}_{2}\right)_{2} \mathrm{CO}(35$ $\mathrm{mg} \mathrm{L}^{-1}$ ) was used to simulate medium strength wastewater with a total organic carbon (TOC), total nitrogen (TN) and chemical oxygen demand (COD) of approximately 180, 25 and $600 \mathrm{mg}$ $\mathrm{L}^{-1}$, respectively. The composition of this synthetic wastewater is similar to that used by other researchers (Johir et al., 2012, Navaratna et al., 2012).

A set of 22 TrOC was selected for investigation based on their widespread occurrence in raw sewage and sewage-impacted water bodies (Ying et al., 2009, Stamatis et al., 2010) and their diverse physicochemical properties (e.g. hydrophobicity and molecular weight) as presented in Table 1 . These compounds represent four major groups of TrOC, namely pharmaceutically active compounds (PhACs), steroid hormones, pesticides and industrial chemicals. A stock solution of all TrOC was prepared in pure methanol at a concentration of $1 \mathrm{~g} \mathrm{~L}^{-1}$ each on a monthly basis and stored at $-18{ }^{\circ} \mathrm{C}$. The stock solution was introduced to the synthetic wastewater to achieve a concentration of approximately $5 \mu \mathrm{g} \mathrm{L}^{-1}$ of each compound.

\section{[TABLE 1]}

\subsection{MBR system and experimental protocol}

The laboratory scale MBR system used in this study consisted of a glass reactor with an active volume of $4.5 \mathrm{~L}$ and a submerged PVDF hollow fiber membrane module (Mitsubishi Rayon Engineering, Japan). The nominal pore size and total surface area of the membrane module were $0.4 \mu \mathrm{m}$ and $0.074 \mathrm{~m}^{2}$, respectively. The membrane was operated on a $14 \mathrm{~min}$ "suction" and $1 \mathrm{~min}$ "relaxation" cycle under an average flux of $0.07 \mathrm{~m} \mathrm{~d}^{-1}$, resulting in a hydraulic retention time (HRT) of $24 \mathrm{~h}$. The transmembrane pressure (TMP) was continuously monitored using a highresolution $( \pm 0.1 \mathrm{kPa}$ ) pressure sensor (SPER scientific 840064, Extech equipment Pty. Ltd, Victoria, Australia).

The MBR was seeded with activated sludge from a municipal wastewater treatment plant in Australia. Air was supplied via a diffuser located at the bottom of the aeration tank to maintain a 
dissolved oxygen (DO) concentration of greater than $3 \mathrm{mg} \mathrm{L}^{-1}$ throughout the operation period. The temperature of the mixed liquor was maintained at $22 \pm 0.1{ }^{\circ} \mathrm{C}$. The $\mathrm{pH}$ of the mixed liquor remained stable within the range of 7.2 - 7.5. The current study was conducted in four phases: initial start-up and acclimatisation (51 days), and evaluation of TrOC removal by MBR-only treatment (135 days), by MBR - UV oxidation (5 days), and by finally MBR-NF/RO operation ( 5 days). At the end of the initial start-up and acclimatisation phase, the mixed liquor suspended solids (MLSS) concentration was $5 \mathrm{~g} \mathrm{~L}^{-1}$. This was maintained at this level until the end of the study.

\subsection{UV oxidation set up and operation protocol}

A laboratory-scale UV oxidation system (Figure 1) supplied by Ace Glass (Vineland, NJ, USA) was coupled in series with the MBR system described above. The system consisted of a reactor and a low-pressure mercury lamp. The reactor had an effective volume of $0.4 \mathrm{~L}$. The lowpressure mercury lamp had a length, total UV energy output and UV intensity of $27 \mathrm{~cm}, 83 \mathrm{~W}$, and $1.04 \mathrm{~W} \mathrm{~cm}^{-2}$, respectively. It emitted UV light in a narrow band at $254 \mathrm{~nm}$. The lamp was placed inside the inner borosilicate glass chamber and was effectively cooled by a water stream circulating through a double-walled compartment surrounding it, acting as a cooling water jacket and keeping the test solution at $20 \pm 0.1^{\circ} \mathrm{C}$.

MBR permeate was continuously pumped into the external cylindrical reaction vessel. The flow rate was set at $7 \mathrm{~mL} \mathrm{~min}{ }^{-1}$ resulting in a contact time of $7.5 \mathrm{~min}$ and $500 \mathrm{~mL}$ of sample was collected for analysis after at least $2 \mathrm{hr}$ of continuous operation. In addition to the experiment with MBR permeate, the raw synthetic wastewater (MBR influent) was run through the UV unit directly using a contact time of $7.5 \mathrm{~min}$.

\section{[FIGURE 1]}

\subsection{NF/RO set up and operation protocol}

A laboratory-scale crossflow membrane filtration system with a rectangular stainless steel crossflow cell was used in this study. Flat sheet samples of NF270 and BW30 were obtained from Dow Filmtec (Minnesota, USA). NF270 is a loose NF membrane while BW30 is a brackish water RO membrane. The detailed characteristics of these two membranes and further information about the crossflow membrane filtration system are available elsewhere (Tu et al., 2011). The MBR permeate was collected and kept in the dark at $-4{ }^{\circ} \mathrm{C}$ prior to $\mathrm{NF} / \mathrm{RO}$ 
membrane filtration experiments within the following day. Prior to each NF/RO experiment, the membrane was compacted using Milli-Q water for approximately $1 \mathrm{~h}$. The compacting permeate flux was $80 \mathrm{~L} \mathrm{~m}^{-2} \mathrm{~h}^{-1}$ for NF 270 and $40 \mathrm{~L} \mathrm{~m}^{-2} \mathrm{~h}^{-1}$ for BW 30. The Milli-Q water used for membrane compaction was then replaced with $6 \mathrm{~L}$ of MBR permeate. The permeate flux was adjusted to $40 \mathrm{~L} \mathrm{~m}^{-2} \mathrm{~h}^{-1}$ for NF 270 and $20 \mathrm{~L} \mathrm{~m}^{-2} \mathrm{~h}^{-1}$ for BW30. The feed reservoir temperature was kept constant at $20 \pm 0.1{ }^{\circ} \mathrm{C}$ throughout the experiment. Permeate and feed samples of 500 $\mathrm{mL}$ were collected after 1 and $25 \mathrm{~h}$ of filtration and were extracted into SPE cartridges for further analysis.

\subsection{Analytical methods}

Basic parameters including total organic carbon (TOC), total nitrogen (TN), mixed liquor suspended solids (MLSS), and mixed liquor volatile suspended solids (MLVSS) were measured according to standard methods (Andrew and Mary, 2005).

The concentrations of the TrOC in MBR, UV, MBR-UV and MBR-NF/RO influent and permeate samples were measured by a previously reported analytical technique involving solid phase extraction, derivatisation and quantitative determination by a Shimadzu GC/MS (QP5000) system (Hai et al., 2011). The GC/MS system was equipped with a Shimadzu AOC 20i autosampler and a Phenomenex Zebron ZB-5 (5\% diphenyl-95\% dimethylpolysiloxane) capillary column $\left(30 \mathrm{~m} \times 0.25 \mathrm{~mm} \mathrm{ID}, \mathrm{d}_{\mathrm{f}}=0.25 \mu \mathrm{m}\right)$ was used. The quantitative detection limits

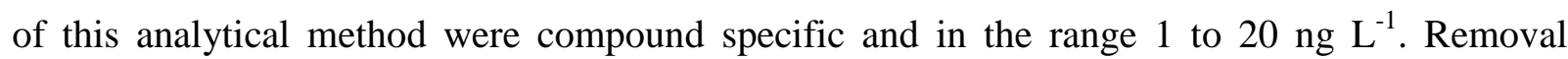
efficiency was calculated as $R=100 \times\left(1-\frac{C_{E f f}}{C_{I n f}}\right)$, where $\mathrm{C}_{\text {Inf }}$ and $\mathrm{C}_{\mathrm{Eff}}$ are influent and effluent (permeate) concentrations of the trace organics, respectively.

\section{Results and discussion}

\subsection{TrOC removal by MBR treatment}

The MBR showed good and stable performance with respect to a range of basic water quality parameters and operating parameters over the entire experiment (Table 2). The TOC removal efficiency was $98 \pm 2 \%$. The effluent turbidity was consistently below 0.2 NTU while the MLVSS/MLSS ratio was also stable at $0.89 \pm 0.03$. The removal efficiencies of the 22 TrOC selected in this study by MBR treatment were also stable as evidenced by the small variation throughout over six months of continuous operation (Figure 2). In good agreement with a 
previous study by Tadkaew et al. (2011), all nine hydrophobic (Log $D>3.2)$ TrOC were well removed by MBR treatment, while the removal efficiencies of the remaining $13 \operatorname{TrOC}(\log D<$ 3.2) varied widely from almost complete removal (e.g. salicylic acid and gemifibrozil) to less than $20 \%$ (e.g. fenoprop and diclofenac). These results are consistent with the literature (Clara et al., 2005, Reif et al., 2008, Hai et al., 2011, Tadkaew et al., 2011) and clearly highlight the need for a post-treatment step to complement MBR treatment for enhanced removal of biologically persistent and hydrophilic TrOC.

\section{[TABLE 2]}

\section{[FIGURE 2]}

\subsection{Removal of TrOC by MBR-UV oxidation system}

Degradation of the 22 TrOC selected in this study by direct UV oxidation is shown in Figure 3. Their removal efficiencies achieved with direct UV oxidation varied significantly from as low as only $30 \%$ (carbamazepine) to almost $100 \%$ (e.g. pentachlorophenol and triclosan). In good agreement with a previous study by Lekkerkerker-Teunissen et al. (2012) the results in Figure 3 demonstrate that UV oxidation can be effective for many but not all TrOC. Variation in the removal efficiency of the 22 TrOC investigated here can be attributed to their physicochemical properties and molecular structures. However, in contrast to the removal of TrOC by MBR treatment, the hydrophobicity of the TrOC does not seem to play any significant role in governing their removal by UV oxidation (Figure 3). Photodegradation efficiencies of compounds which have similar molecular features can be very similar because of cleavage of the same covalent bond or molecular moiety (Kim and Tanaka, 2009). In fact, all 11 TrOC that contain a phenolic moiety (i.e. a hydroxyl functional group attached to a benzene ring) were well removed (i.e. $78 \%$ to almost complete removal) by direct UV oxidation. These include the four industrial chemicals and their metabolites, all five steroid hormones, pentachlorophenol and salicylic acid. The UV lamp used in this study emitted UV light in a narrow band at $254 \mathrm{~nm}$ which is significantly adsorbed by the aromatic benzene ring. The presence of the hydroxyl functional group in the benzene ring of these 11 TrOC make them more amenable to photodegradation by hydrogen abstraction. It is noteworthy that although chlorinated $\mathrm{TrOC}$ were resistant to MBR treatment, they were well removed by UV oxidation. Indeed, the removal efficiencies of all four chlorinated TrOC (i.e. diclofenac, triclosan, fenoprop and 
pentachlorophenol) by UV oxidation were above $85 \%$. This is consistent with the pathway previously suggested for the UV oxidation of these halogenated compounds which involves substitution of halogens and subsequent dealkylation mechanisms (Vogna et al., 2004b, Lekkerkerker-Teunissen et al., 2012). Vogna et al. (2004b) investigated the degradation of diclofenac under UV oxidation (with and without $\mathrm{H}_{2} \mathrm{O}_{2}$ addition) and provided direct evidence of this mechanism. They observed an increase in the concentration of free chloride following UV oxidation of a diclofenac solution indicating cleavage of $\mathrm{Cl}$ from the benzene ring (Vogna et al., 2004b).

It is noteworthy that the UV oxidation efficiency of carbamazepine was only $30 \pm 7 \%$. Similar to our study, Vogna et al. (2004a) observed that UV oxidation was not effective in reducing the carbamazepine concentration. The photodegradation efficiency of carbamazepine was $8 \%$ and $36 \%$ using two UV lights at wavelengths of $254 \mathrm{~nm}$ and $185 \mathrm{~nm}$, respectively. The resistance of carbamazepine may be attributed to the amide groups in its structure. Kim et al. (2009) reported that two PPCPs with amide bonds (cyclophosphamide and N,N-Diethyl-meta-toluamide (DEET)) were highly resistant to UV oxidation. Amide functional groups are the most stable of the carbonyl containing groups due to the high resonance stabilization between $\mathrm{N}-\mathrm{C}$ and $\mathrm{C}-\mathrm{O}$ bonds, indicating that it would be difficult to degrade TrOC with amide bonds using UV oxidation.

\section{[FIGURE 3]}

Because MBR treatment and UV oxidation are capable of removing TrOC by different degradation mechanisms, a hybrid system involving both these technologies can take advantage of their complementary nature. In fact, as demonstrated in Figure 4, UV oxidation can complement MBR treatment very well, resulting in over $85 \%$ removal efficiency of all 22 TrOC selected in this study, including those that are poorly removed by either MBR treatment or UV oxidation when they are deployed separately. All chlorinated TrOC (i.e. fenoprop, diclofenac, pentachlorophenol and triclosan) were very effectively removed by combined MBR - UV treatment. Therefore, the application of UV oxidation for post-treatment of MBR permeate may be promising for achieving high removal of chlorinated TrOC.

The benefit of combining MBR with UV oxidation can also be showed by examining the removal of carbamazepine (which is a well-known biologically persistent compound). Carbamazepine was poorly removed by either MBR treatment or UV oxidation when they were deployed separately. 
The removal efficiency of carbamazepine by MBR and UV only was $32 \pm 17 \%$ (Figure 2) and $30 \pm 7 \%$ (Figure 3), respectively. By contrast, treatment by the UV system at a contacting time of 7.5 min following MBR attained exceptionally high removal efficiency and resulted in an overall removal of carbamazepine of $96 \%$, which is significantly higher than that achieved by either treatment process separately.

It is noteworthy that MBR treatment can provide a low background organic matter content and suspended solids free influent (Melin et al., 2006) which is highly suitable as an influent for the UV oxidation process. The presence of suspended solids in the influent can absorb and scatter UV radiation thus reducing the overall process efficiency (Ling et al., 2004). Chowdhury et al. (2011) observed that the degradation of 17- $\beta$-estradiol decreased with increasing turbidity in the test solution. Rincon et al. (2003) also reported that water turbidity higher than 30 NTU will severely affect the efficiency of photocatalytic disinfection. The turbidity of the synthetic wastewater and MBR permeate in this study were 1 and less than 0.2 NTU, respectively. Therefore, the effect of turbidity is considered to be insignificant in this experiment. The enhanced removal of carbamazepine from MBR permeate by UV oxidation can be attributed to the fact that there is less bulk organic compounds/content in MBR permeate compared to MBR feed. The bulk organic matter in the MBR feed may compete for UV light adsorption. Yuan et al. (2009) reported that the presence of humic acid reduced the UV oxidation efficiency of ibuprofen due to the competition of humic acid for the UV light.

\section{[FIGURE 4]}

\subsection{Removal of TrOC by $M B R-N F / R O$ treatment}

Several previous studies have demonstrated that MBRs can effectively remove hydrophobic and readily biodegradable TrOC, while significant variation in removal of hydrophilic and biologically persistent TrOC have been observed (Clara et al., 2005, Alturki et al., 2010, Tadkaew et al., 2011, Nguyen et al., 2012). Our results confirm the high removal efficiency of all the steroid hormones, alkyl phenolic surfactants and industrial chemicals (Log D > 3.2) and readily biodegradable hydrophilic TrOC after a long term operation of MBR (196 days). Figure 2 also highlights the low and/or variable removal of biologically persistent TrOC (i.e. metronidazole, fenoprop, ketoprofen, naproxen, diclofenac and carbamazepine). 
High removal of hydrophobic TrOC at the initial stage of direct filtration by NF/RO membrane can be observed due to steric hindrance and their adsorption onto the membrane polymeric matrix (Nghiem et al., 2004, Jin et al., 2010). However, the adsorption effect can only contribute to the short term removal; as the feed is continuously filtered through the membrane, membrane sites will be saturated with hydrophobic TrOC (Nghiem et al., 2004, Jin et al., 2010). On the other hand, the hydrophilic TrOC do not adsorb to the membrane polymeric matrix and can be effectively removed by NF/RO membranes via steric hindrance or size exclusion mechanisms. Because MBR permeate is free from hydrophobic TrOC, and the hydrophilic TrOC which are resistant to MBR treatment can be effectively removed by the $\mathrm{NF} / \mathrm{RO}$ membranes, there is a potential for coupling MBR with NF/RO to achieve an enhanced removal of TrOC. As can be observed in Figure 5 the NF/RO membrane treatment complements MBR treatment very well, with the majority of the 22 TrOC selected in this study being removed to below the detection limits (of below $20 \mathrm{ng} / \mathrm{L}$ ). Notably, insignificant differences in the removal efficiencies after 1 and $25 \mathrm{~h}$ of NF/RO filtration were observed (data not shown). In other words, steady state removal efficiency had been obtained.

The MBR-BW30 achieved higher removal efficiencies of TrOC such as some hydrophilic compounds (e., metronidazole, acetaminophen and carbamazepine) than the MBR-NF270. Our observation is in good agreement with previous reports (Alturki et al., 2010) and can be explained by the fact that NF270 is a loose membrane with a larger pore size and a higher permeability. This is also supported by the low conductivity rejection by the NF270 membrane (41-49\%) compared to the BW30 membrane (93-94\%).

\section{[FIGURE 5]}

\section{Conclusions}

This study confirms effective removal of the hydrophobic and readily biodegradable TrOC and the unstable removal of the biologically persistent and hydrophilic TrOC by MBR treatment. Results reported here also indicate that UV oxidation is effective for the oxidation of a range of TrOC; however, the removal efficiency may vary depending on the compound physicochemical properties and molecular structures. UV oxidation was effective for the degradation of chlorinated TrOC and TrOC with a phenolic group in their molecular structure but less effective for the removal of amide-containing TrOC (e.g. carbamazepine). UV oxidation and NF/RO 
membrane filtration was observed to significantly complement MBR treatment to obtain high overall removal of hydrophilic and biologically persistent TrOC. MBR treatment and direct UV oxidation, by themselves achieved a low removal of carbamazepine, whilst their combination resulted in more than $96 \%$ removal.

\section{Acknowledgement}

A postgraduate scholarship to Luong Nguyen from the University of Wollongong, Australia and the Thanh Hoa provincial government (Vietnam) is greatly appreciated. Mitsubishi Rayon Engineering (Tokyo, Japan) and Dow Filmtec (Minnesota, USA) are thanked for the provision of membrane samples.

\section{References}

Al-Rifai, J. H., Khabbaz, H. \& Schäfer, A. I. 2011. Removal of pharmaceuticals and endocrine disrupting compounds in a water recycling process using reverse osmosis systems. Separation and Purification Technology, 77, 60-67.

Alturki, A. A., Tadkaew, N., McDonald, J. A., Khan, S. J., Price, W. E. \& Nghiem, L. D. 2010. Combining MBR and NF/RO membrane filtration for the removal of trace organics in indirect potable water reuse applications. Journal of Membrane Science, 365, 206-215.

Andrew, D. E. \& Mary, A. H. F. 2005. Standard Methods for the Examnination of Water and Wastewater, American Public Health Association.

Basile, T., Petrella, A., Petrella, M., Boghetich, G., Petruzzelli, V., Colasuonno, S. \& Petruzzelli, D. 2011. Review of Endocrine Disrupting Compound Removal Technologies in Water and Wastewater Treatment Plants: An EU Perspective. Industrial and Engineering Chemistry Research, 50, 8389-8401.

Bellona, C., Drewes, J. E., Xu, P. \& Amy, G. 2004. Factors affecting the rejection of organic solutes during NF/RO treatment—a literature review. Water Research, 38, 2795-2809.

Bellona, C., Drewes, J. E., Oelker, G., Luna, J., Filteau, G. \& Amy, G. 2008. Comparing nanofiltration and reverse osmosis for drinking water augmentation. Journal - American Water Works Association, 100, 102-116.

Beltrain, F. J., Garca-Araya, J. F. \& Acedo, B. 1994. Advanced oxidation of atrazine in water II. Ozonation combined with ultraviolet radiation. Water Research, 28, 2165-2174. 
Cater, S. R., Stefan, M. I., Bolton, J. R. \& Safarzadeh-Amiri, A. 2000. UV/ $\mathrm{H}_{2} \mathrm{O}_{2}$ Treatment of Methyl tert-Butyl Ether in Contaminated Waters. Environmental Science and Technology, 34, 659-662.

Chong, M. N., Jin, B., Chow, C. W. K. \& Saint, C. 2010. Recent developments in photocatalytic water treatment technology: A review. Water Research, 44, 2997-3027.

Chowdhury, R. R., Charpentier, P. A. \& Ray, M. B. 2011. Photodegradation of 17b-estradiol in aquatic solution under solar irradiation: Kinetics and influencing water parameters. Journal of Photochemistry and Photobiology A: Chemistry, 219, 67-75.

Clara, M., Strenn, B., Gans, O., Martinez, E., Kreuzinger, N. \& Kroiss, H. 2005. Removal of selected pharmaceuticals, fragrances and endocrine disrupting compounds in a membrane bioreactor and conventional wastewater treatment plants. Water Research, 39, 4797-4807.

Hai, F. I., Tessmer, K., Nguyen, L. N., Kang, J., Price, W. E. \& Nghiem, L. D. 2011. Removal of micropollutants by membrane bioreactor under temperature variation. Journal of Membrance Science, 383, 144-151.

Jin, X., Hu, J. \& Ong, S. L. 2010. Removal of natural hormone estrone from secondary effluents using nanofiltration and reverse osmosis. Water Research, 44, 638-648.

Johir, M. A. H., Vigneswaran, S., Sathasivan, A., Kandasamy, J. \& Chang, C. Y. 2012. Effect of organic loading rate on organic matter and foulant characteristics in membrane bioreactor. Bioresource Technology, 113, 154-160.

Kim, I. \& Tanaka, H. 2009. Photodegradation characteristics of PPCPs in water with UV treatment. Environment International, 35, 793-802.

Köhler, C., Venditti, S., Igos, E., Klepiszewski, K., Benetto, E. \& Cornelissen, A. 2012. Elimination of pharmaceutical residues in biologically pre-treated hospital wastewater using advanced UV irradiation technology: A comparative assessment. Journal of Hazardous Materials, In press.

Laera, G., Chong, M. N., Jin, B. \& Lopez, A. 2011. An integrated $M B R-T_{2} O_{2}$ photocatalysis process for the removal of Carbamazepine from simulated pharmaceutical industrial effluent. Bioresource Technology, 102, 7012-7015. 
Lekkerkerker-Teunissen, K., Benotti, M. J., Snyder, S. A. \& van Dijk, H. C. 2012. Transformation of atrazine, carbamazepine, diclofenac and sulfamethoxazole by low and medium pressure UV and $\mathrm{UV} / \mathrm{H}_{2} \mathrm{O}_{2}$ treatment. Separation and Purification Technology, 96, 33-43.

Ling, C. M., Mohamed, A. R. \& Bhatia, S. 2004. Performance of photocatalytic reactors using immobilized $\mathrm{TiO}_{2}$ film for the degradation of phenol and methylene blue dye present in water stream. Chemosphere, 57, 547-554.

Melin, T., Jefferson, B., Bixio, D., Thoeye, C., De Wilde, W., De Koning, J., van der Graaf, J. \& Wintgens, T. 2006. Membrane bioreactor technology for wastewater treatment and reuse. Desalination, 187, 271-282.

Navaratna, D., Shu, L., Baskaran, K. \& Jegatheesan, V. 2012. Model development and parameter estimation for a hybrid submerged membrane bioreactor treating Ametryn. Bioresource Technology, 113, 191-200.

Nghiem, L. D., Schafer, A. I. \& Elimelech, M. 2004. Removal of Natural Hormones by Nanofiltration Membranes: Measurement, Modeling, and Mechanisms. Environmental Science and Technology, 38, 1888-1896.

Nguyen, L. N., Hai, F. I., Kang, J., Price, W. E. \& Nghiem, L. D. 2012. Removal of trace organic contaminants by a membrane bioreactor-granular activated carbon (MBR-GAC) system. Bioresource Technology, 113, 169-173.

Packer, J. L., Werner, J. J., Latch, D. E., McNeill, K. \& Arnold, W. A. 2003. Photochemical fate of pharmaceuticals in the environment: Naproxen, diclofenac, clofibric acid, and ibuprofen. Aquatic Science, 65, 342-351.

Paxéus, N. 2004. Removal of selected non-steroidal anti-inflammatory drugs (NSAIDs), gemfibrozil, carbamazepine, beta-blockers, trimethoprim and triclosan in conventional wastewater treatment plants in five EU countries and their discharge to the aquatic environment. Water Sci Technol, 50, 253-60.

Reif, R., Suairez, S., Omil, F. \& Lema, J. M. 2008. Fate of pharmaceuticals and cosmetic ingredients during the operation of a MBR treating sewage. Desalination, 221, 511-517. 
Rincon, A. G. \& Pulgarin, C. 2003. Photocatalytical inactivation of E. coli: effect of (continuous - intermittent) light intensity and of (suspended - fixed) $\mathrm{TiO}_{2}$ concentration. Applied Catalysis B-Environmental, 44, 263-284.

Sahar, E., Ernst, M., Godehardt, M., Hein, A., Herr, J., Kazner, C., Melin, T., Cikurel, H., Aharoni, A., Messalem, R., Brenner, A. \& Jekel, M. 2011. Comparison of two treatments for the removal of selected organic micropollutants and bulk organic matter: conventional activated sludge followed by ultrafiltration versus membrane bioreactor. Water Science \& Technology, 63, 733-740.

Schwarzenbach, R. P., Thomas, E., Thomas, H., Urs Von, G. \& Bernhard, W. 2010. Global Water Pollution and Human Health. Annual Review of Environment and Resources, 35, 109-136.

Shannon, M. A., Bohn, P. W., Elimelech, M., Georgiadis, J. G., Marinas, B. J. \& Mayes, A. M. 2008. Science and technology for water purification in the coming decades. Nature, 452 , 301-310.

Stamatis, N., Hela, D. \& Konstantinou, I. 2010. Occurrence and removal of fungicides in municipal sewage treatment plant. Journal of Hazardous Materials, 175, 829-835.

Tadkaew, N., Hai, F. I., McDonald, J. A., Khan, S. J. \& Nghiem, L. D. 2011. Removal of trace organics by MBR treatment: The role of molecular properties. Water Research, 45, 24392451 .

Ternes, T. A., Meisenheimer, M., McDowell, D., Sacher, F., Brauch, H.-J., Haist-Gulde, B., Preuss, G., Wilme, U. \& Zulei-Seibert, N. 2002. Removal of Pharmaceuticals during Drinking Water Treatment. Environmental Science \& Technology, 36, 3855-3863.

Thoma, K. \& Kübler, N. 1997. Photostability of antifungal agents. 2.Photostability of polyene antibiotics. Pharmazie, 52, 294-302.

Tu, K. L., Nghiem, L. D. \& Chivas, A. R. 2011. Coupling effects of feed solution pH and ionic strength on the rejection of boron by NF/RO membranes. Chemical Engineering Journal, 168, 700-706. 
Visvanathan, C., Aim, R. B. \& Parameshwaran, K. 2000. Membrane Separation Bioreactors for Wastewater Treatment. Critical Reviews in Environmental Science and Technology, 30, $1-48$.

Vogna, D., Marotta, R., Andreozzi, R., Napolitano, A. \& d'Ischia, M. 2004a. Kinetic and chemical assessment of the $\mathrm{UV} / \mathrm{H}_{2} \mathrm{O}_{2}$ treatment of antiepileptic drug carbamazepine. Chemosphere, 54, 497-505.

Vogna, D., Marotta, R., Napolitano, A., Andreozzi, R. \& d'Ischia, M. 2004b. Advanced oxidation of the pharmaceutical drug diclofenac with $\mathrm{UV} / \mathrm{H}_{2} \mathrm{O}_{2}$ and ozone. Water Research, 38, 414-422.

Wu, C. \& Linden, K. G. 2008. Degradation and byproduct formation of parathion in aqueous solutions by $\mathrm{UV}$ and $\mathrm{UV} / \mathrm{H}_{2} \mathrm{O}_{2}$ treatment. Water Research, 42, 4780-4790.

Ying, G.-G., Kookana, R. S. \& Kolpin, D. W. 2009. Occurrence and removal of pharmaceutically active compounds in sewage treatment plants with different technologies. Journal of Environmental Monitoring, 11, 1498-1505.

Yuan, F., Hu, C., Hu, X., Qu, J. \& Yang, M. 2009. Degradation of selected pharmaceuticals in aqueous solution with $\mathrm{UV}$ and $\mathrm{UV} / \mathrm{H}_{2} \mathrm{O}_{2}$. Water Research, 43, 1766-1774. 
LIST OF TABLES

Table 1: Physicochemical properties of the 22 TrOC.

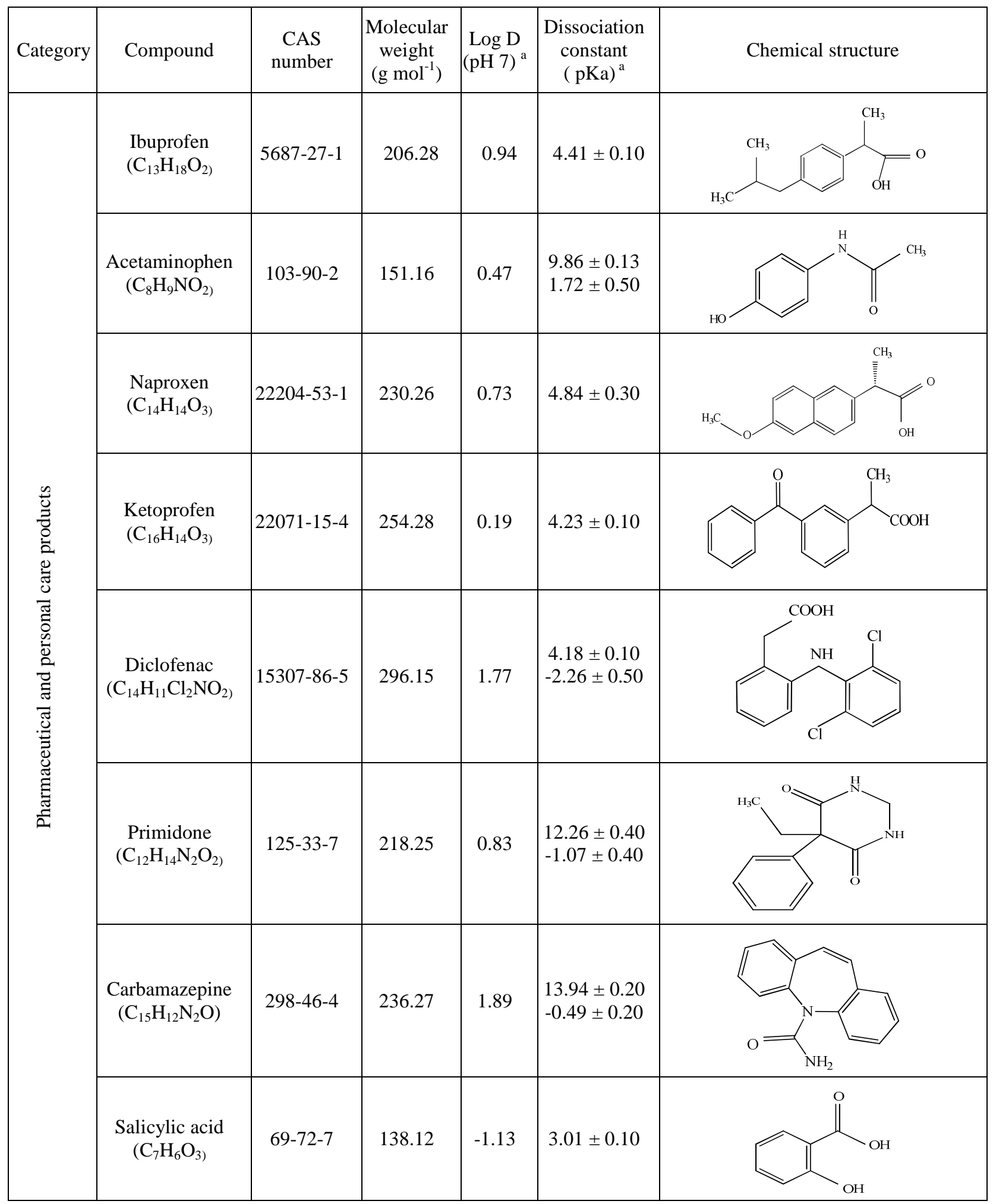




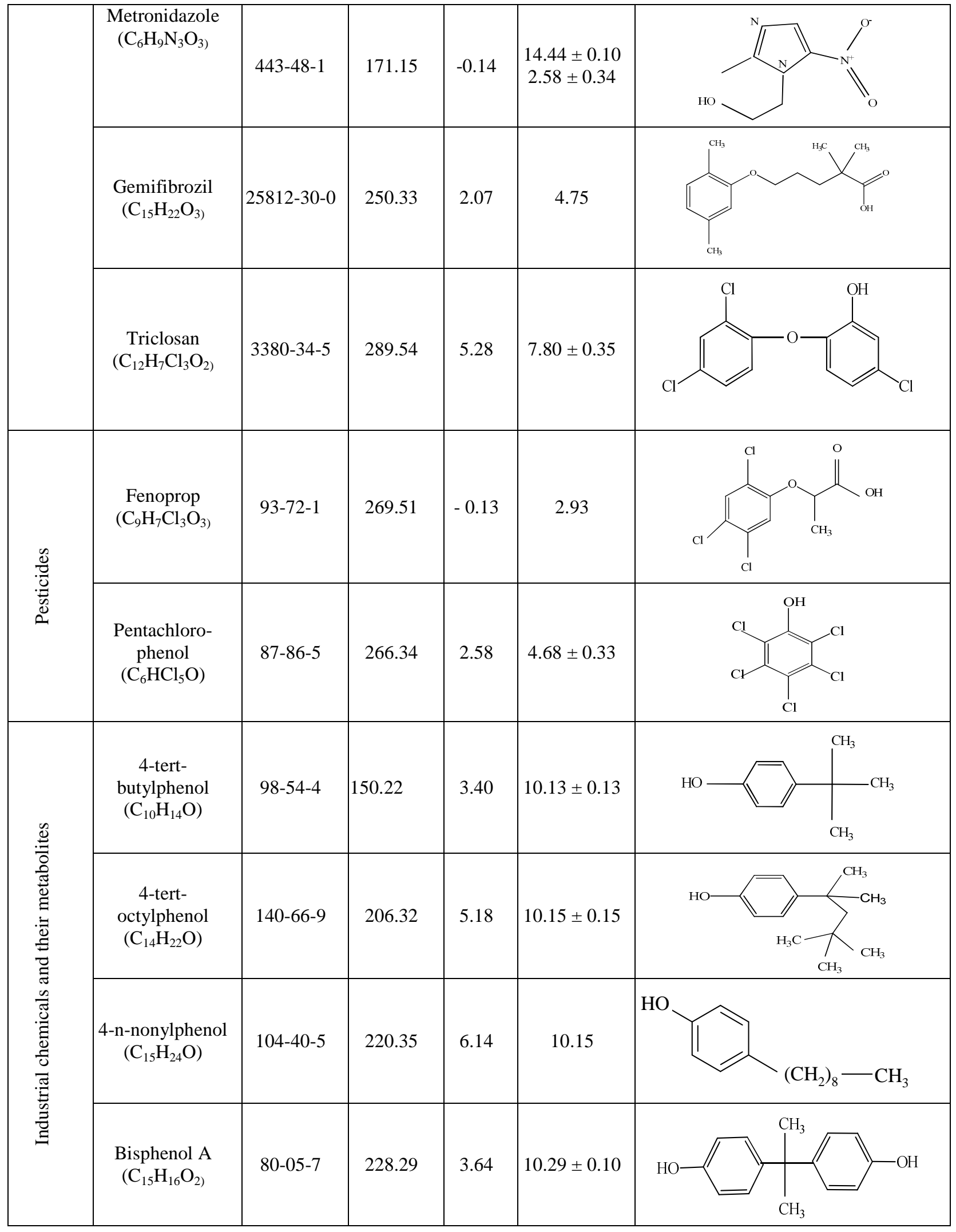




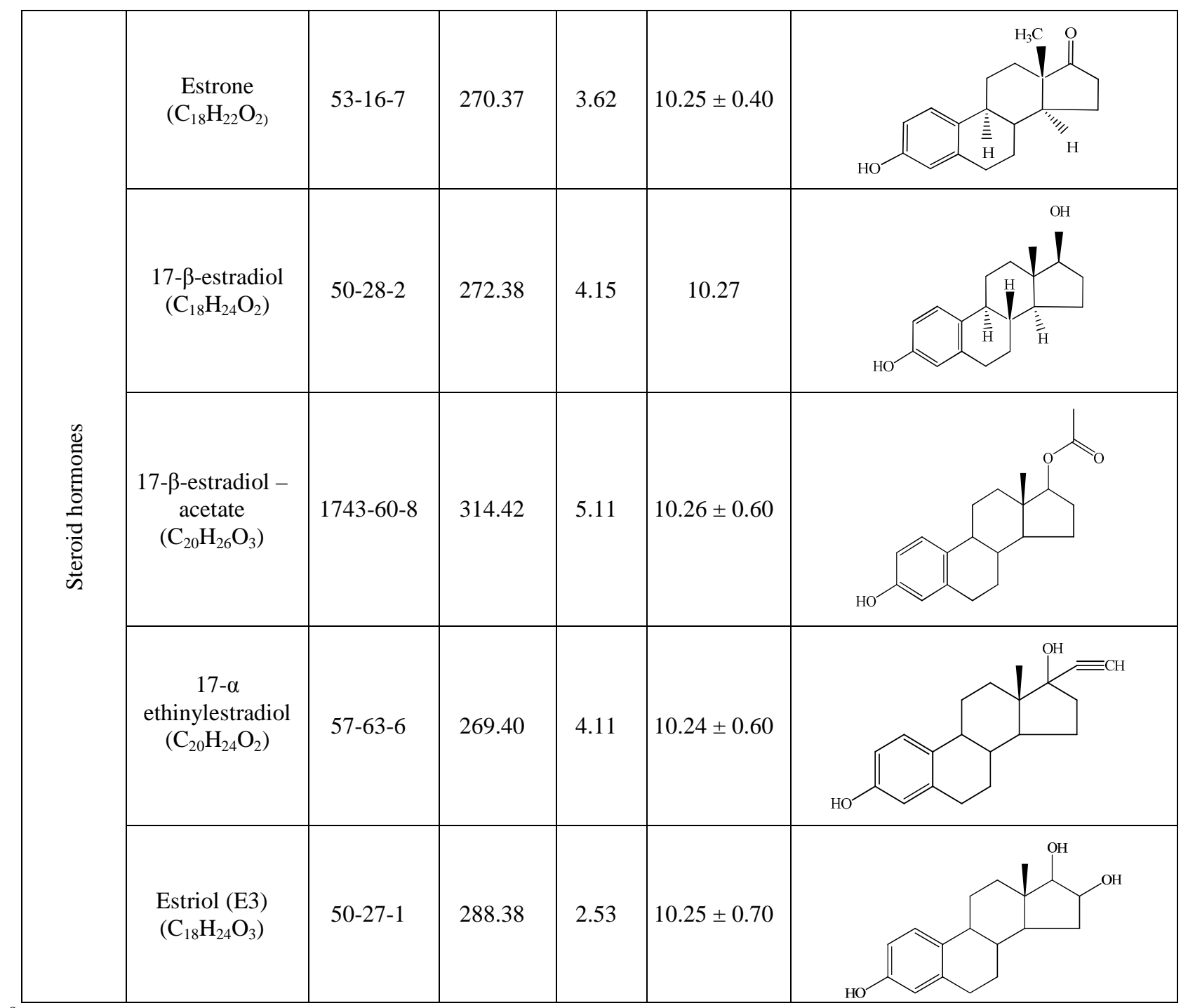

${ }^{a}$ Source: SciFinder (https://scifinder.cas.org/scifinder/view/scifinder/scifinderExplore.jsf)

${ }^{\mathrm{b}}$ Source: http://chem.sis.nlm.nih.gov/chemidplus/

na: data not available 
Table 2: Basic biological performance of the MBR during 196 days of continuous operation.

\begin{tabular}{|c|c|c|c|c|c|c|c|}
\hline $\begin{array}{l}\text { TOC } \\
\text { removal } \\
(\%) \\
(\mathrm{n}=58)\end{array}$ & $\begin{array}{c}\mathrm{TN} \\
\text { removal } \\
(\%) \\
(\mathrm{n}=58)\end{array}$ & $\begin{array}{l}\text { MLVSS/ } \\
\text { MLSS } \\
(n=40)\end{array}$ & $\begin{array}{c}\text { Supernatant } \\
\text { turbidity } \\
(\mathrm{NTU}) \\
(\mathrm{n}=58)\end{array}$ & $\begin{array}{c}\text { SVI } \\
(\mathrm{mL})(\mathrm{g} \\
\mathrm{MLSS}^{-1} \\
(\mathrm{n}=10)\end{array}$ & $\begin{array}{c}\text { SOUR } \\
\left(\mathrm{mg} \mathrm{O}_{2}\right) \\
\mathrm{h}^{-1}(\mathrm{~g} \\
\text { MLVSS }^{-} \\
1 \\
(\mathrm{n}=10)\end{array}$ & $\begin{array}{c}\text { Effluent } \\
\text { TOC } \\
\left(\mathrm{mg} \mathrm{L}^{-1}\right) \\
(\mathrm{n}=58)\end{array}$ & $\begin{array}{l}\mathrm{pH} \text { of the } \\
\text { reactor } \\
(\mathrm{n}=21)\end{array}$ \\
\hline $98 \pm 2$ & $46 \pm 15$ & $0.89 \pm 0.03$ & $7 \pm 4$ & $162 \pm 29$ & $14 \pm 3$ & $3 \pm 2$ & $7.4 \pm 0.1$ \\
\hline
\end{tabular}




\section{LIST OF FIGURES}

Figure 1: Schematic of the UV oxidation reactor.

Figure 2: Removal of 22 TrOC by the MBR over 196 days of operation. Error bar represents standard deviation of 40 samples.

Figure 3: Removal of $22 \mathrm{TrOC}$ by the UV system at a contact time of 7.5 minutes. Error bar represents standard deviation of 4 replicate experiments.

Figure 4: Removal of 22 TrOC by the MBR-UV oxidation hybrid system at a contact time of 7.5 minutes in the UV reactor.

Figure 5: Overall removal of $22 \mathrm{TrOC}$ by $\mathrm{MBR}$ treatment followed by (a) nanofiltration membrane (NF 270) and (b) reverse osmosis membrane (BW 30) after $25 \mathrm{~h}$ filtration. 


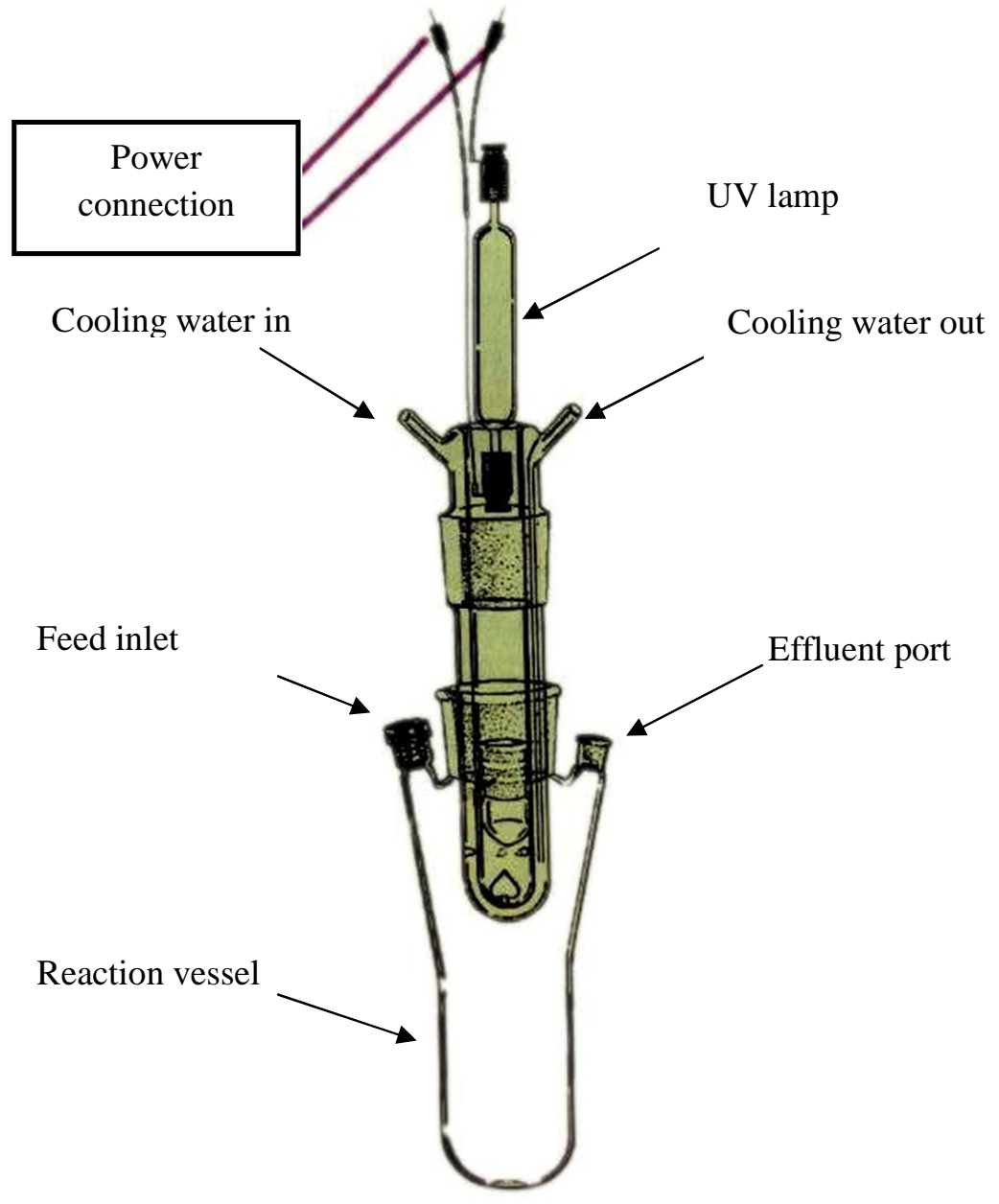

Figure 1 


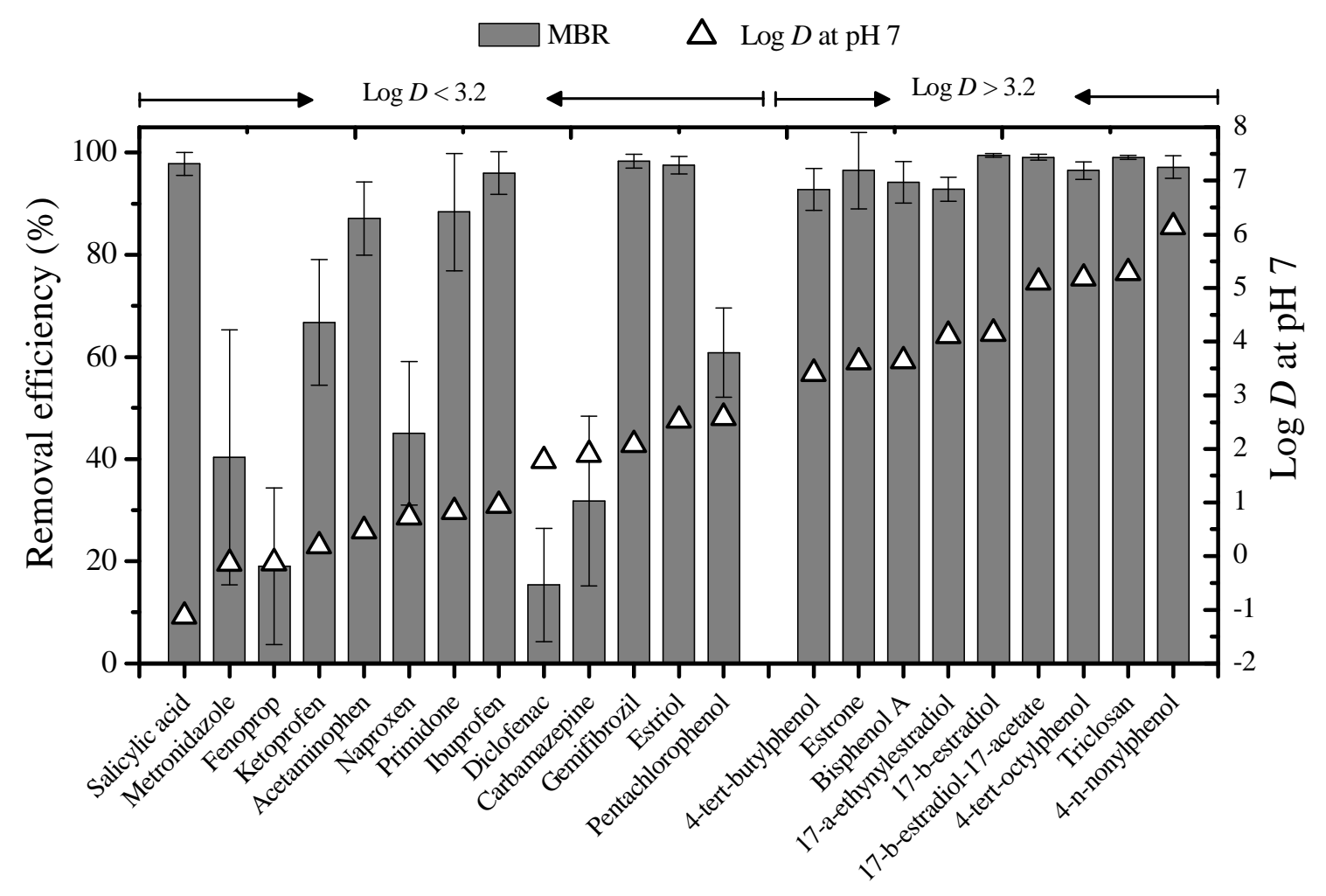

Figure 2 


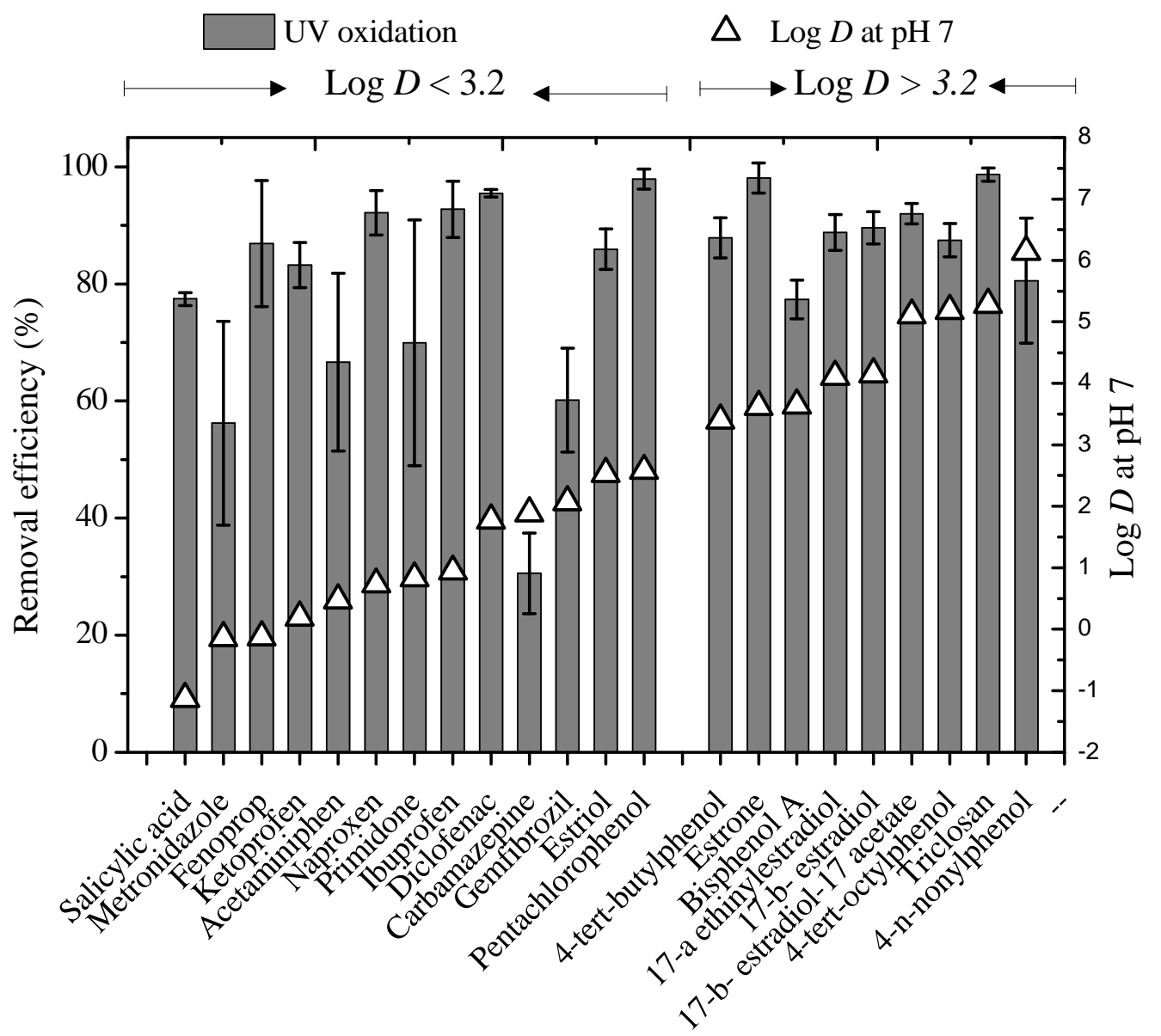

Figure 3 


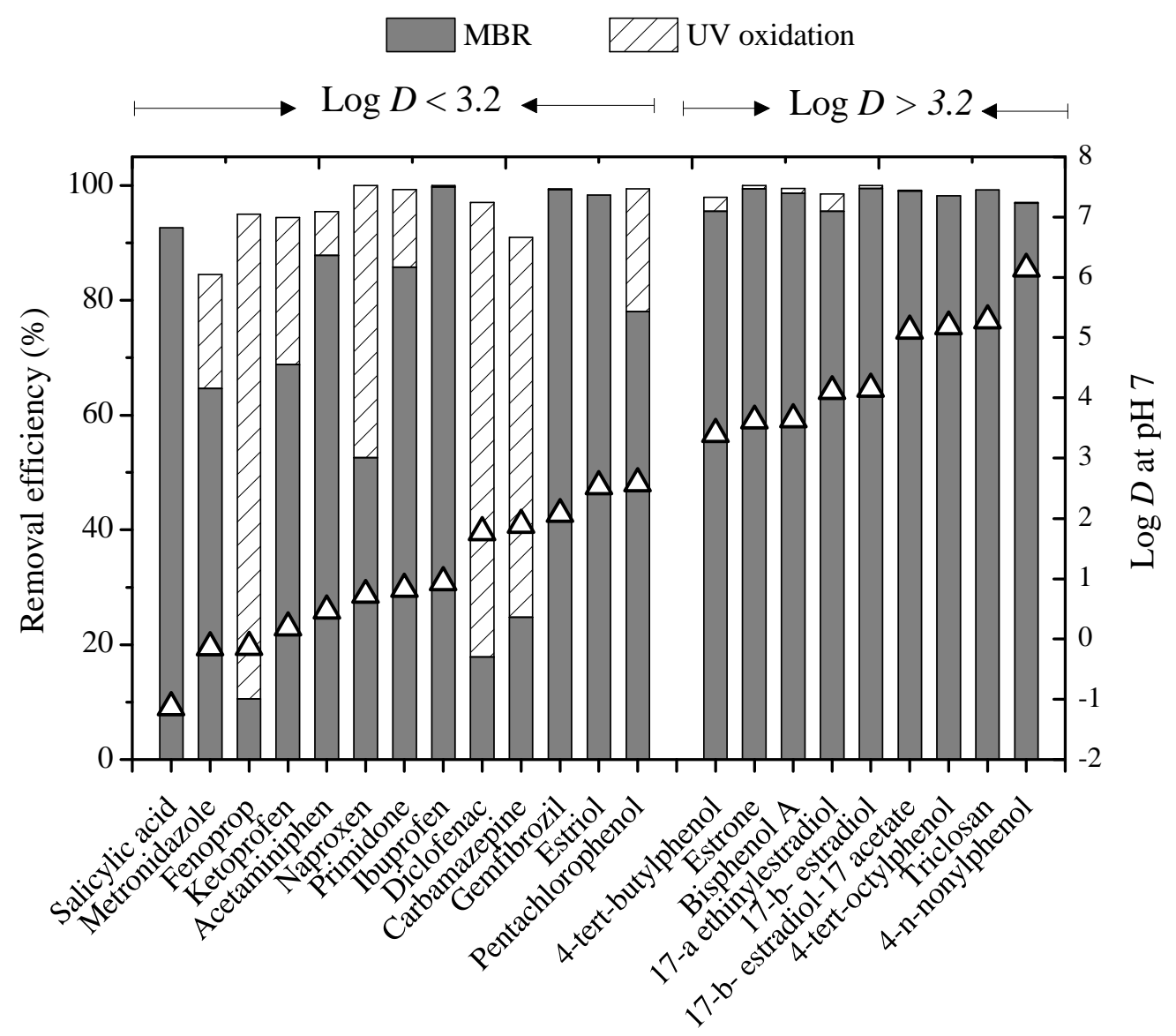

Figure 4 


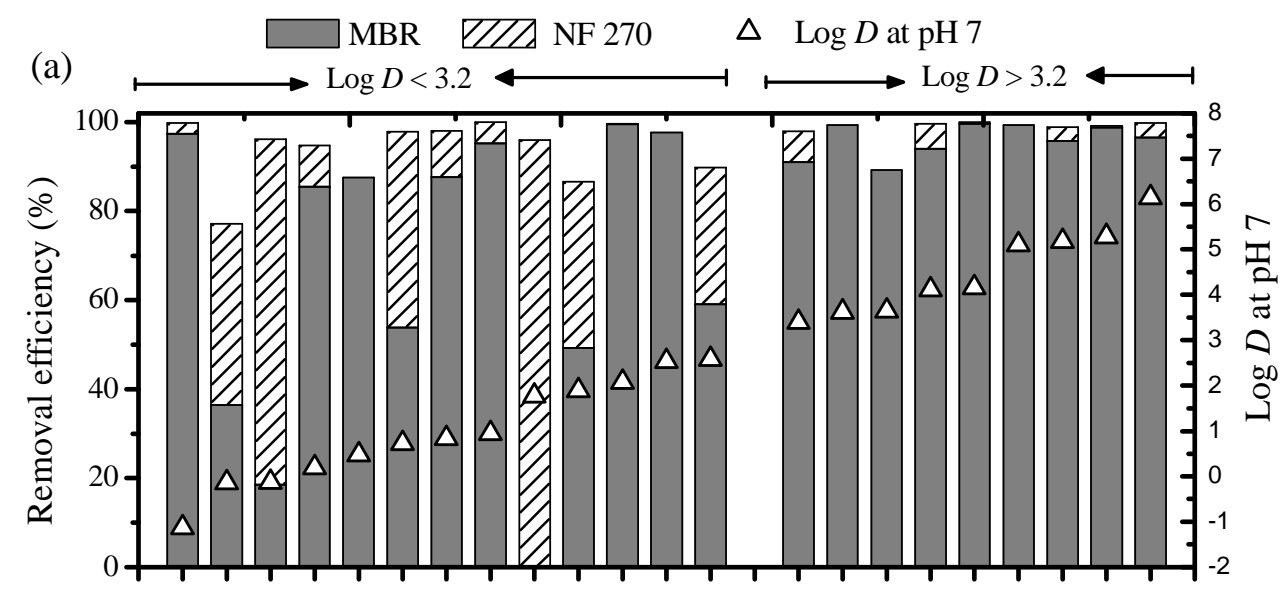

(b)

$\square$ MBR VIIA BW 30

$\triangle \quad \log D$ at $\mathrm{pH} 7$
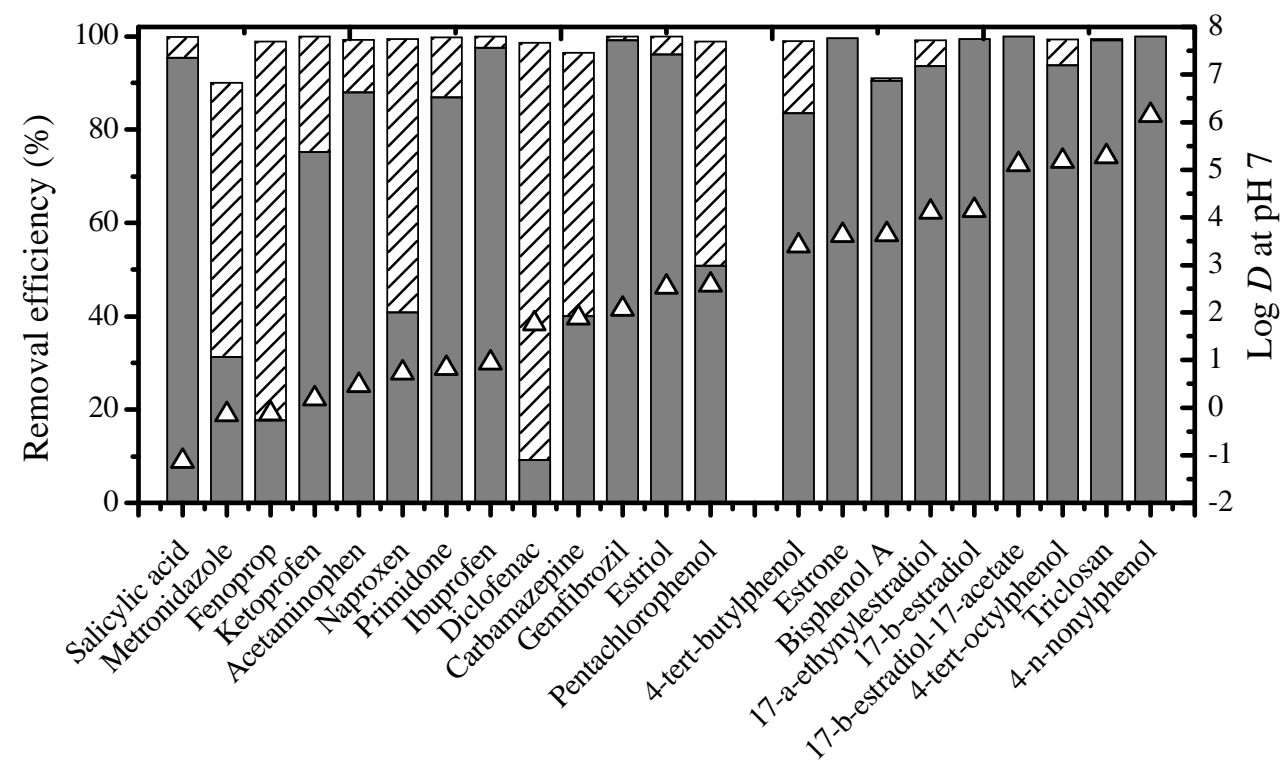

Figure 5 